\title{
Ceramic production in prehistoric northwest China: preliminary findings of new analyses of old material from the Museum of Far Eastern Antiquities, Stockholm
}

\author{
Anke Hein ${ }^{1 *}$, Ole Stilborg ${ }^{2}$ \\ 1. School of Archaeology, University of Oxford, Institute of Archaeology, 36 Beaumont St, OX1 \\ 2PG, Oxford, United Kingdom \\ 2. Department of Archaeology, Stockholm University, Wallenberglaboratoriet, SE-106 91 \\ Stockholm, Sweden \\ * Corresponding author: anke.hein@ arch.ox.ac.uk
}

\begin{abstract}
:
The Neolithic painted pottery of northwest China has long been admired for its high level of craftsmanship. Yet, little is known about the technological processes and potting communities behind these objects. At the same time, the wide variety of supposedly less "beautiful" Bronze Age wares is often disregarded and simply ascribed to the emergence of multiple new cultures. In both cases, the relationship between object appearance, technology, and cultural expectations is unexplored. The present paper presents the first results of a pilot study using a combination of scientific techniques to learn about traditions of ceramic production and their transformation over time and space in prehistoric northwest China.

The basis of this study are finds excavated in the 1920s and held in the Museum of Far Eastern Antiquities in Stockholm. This collection has long lain dormant and their potential remains largely unexplored. This paper draws attention to the collection and at the same time shows the usefulness of combining thin-section petrography and portable X-ray fluorescence for this specific set of material and research questions. This analysis of a small sample already provides important insights. For instance, it shows continuity in criteria of raw material selection during the Neolithic but a radical break in tempering behavior at the transition from early to late Bronze Age. The study also identifies technical challenges as well as possibilities posed by the quality of the local raw material in conjunction with long-standing traditions of high-level local craftsmanship. All of these phenomena, so the paper shows, are best investigated with a combination of petrographic and chemical analyses on archaeological and geological samples viewed in a comparative perspective.
\end{abstract}

Keywords: ceramic technology; northwest China; petrography; P-ED-XRF; Museum of Far Eastern Antiquities; Gansu; Johan Gunnar Andersson

\section{Introduction}

Ceramics are one of the main types of evidence that archaeologists work with on a daily basis. Due to their ubiquity, durability, and chronological sensitivity, even in the age of scientific 
dating methods ceramics still form the basis of many chronological frameworks, especially in Chinese archaeology (Hein, 2016). This tendency to define archaeological cultures based on ceramic types is highly problematic, for the relationship between ceramics and past identity groups is by no means straightforward. Ceramics form a complex entity shaped by the nature of the raw material, the available technology, the abilities and preferences of the potter as well as their ideas of what a specific vessel should look like. These ideas, in turn, are shaped by the users and observers who engage with these wares, all of them acting within various overlapping communities of practice (Wenger, 1998). Research on early ceramics aims to understand these communities and their interplay - both locally and across space and time. Such insights are made possible by the nature of ceramics; they preserve traces of the various production stages, thus allowing for the reconstruction of the chaînes opératoires that created them. Furthermore, individual vessels can be compared to each other and fitted within larger assemblages to reconstruct whole craft traditions (Stilborg 2017: 658-9).

In the research area of the present study, northwest China, the traditional identification of ceramics with cultures still goes largely unchallenged, something that the authors address in this paper by focusing on communities of practice, more specifically potting communities and craft traditions without assuming that these can be equated with larger cultural groups. The area is thought of as an exchange corridor between China and Central Asia, active from the Neolithic onwards and has therefore recently become a focus of scientific research on human movement and dissemination of new technologies and subsistence systems (Atahan et al., 2011; Flad et al., 2010). Northwest China is thus of interest as a case study for issues of culture contact and long-distance interaction. However, in such big-picture debates the role of local developments is often overlooked. The present study focuses on local changes in ceramic production as an indicator for both local social changes and larger regional and super-regional trends. These patterns are reflected in the appearance of painted pottery over large parts of northern China during the Neolithic period as well as its subsequent disappearance.

Neolithic painted pottery from northwest China associated with the Majiayao "culture" or period (c. 3200-2000 BC) has long been admired for its high level of craftsmanship and aesthetic appeal, but little is known about the complex interplay of human actions leading to their production and dissemination. Based on similarity in object forms, decoration motives, and smooth reddish surfaces, painted vessels are usually seen as part of the same ceramic tradition, but it is by no means certain if the techniques used in their production are unchanged over time and space. Similarly, the subsequent Qijia period (c. 2300-1500 BC) is characterized by the occurrence of similar ceramic forms and decorative motives over a wide area usually ascribed to a shared cultural identity (Fitzgerald-Huber 2003). Conversely, the diversification of ceramic forms from the early $2^{\text {nd }}$ mill. BC onward is interpreted as the sudden appearance of many new "cultures", most importantly Xindian (c. 1600-700 BC), Siwa (c. 1600-700 BC), and Kayue (c. 1600-400 BC) (Shui, 2001); however, the nature of the human actions behind these ceramic types is unclear and the associated dates are highly contested (Fiskesjö and Chen, 2004).

For all three periods, the relationship between object appearance, technology, cultural expectations, and social context of production and consumption are largely unexplored. For the Majiayao-style painted wares, based on their high quality and occurrence over wide regions, it has been suggested that they may have been prestige goods sometimes exchanged between elites over 
long distances (Hong et al., 2012). Evidence for such long-distance connections, however, is limited and contested (Ren et al., 2013), and so far, there is no evidence for the presence of production centers that may have distributed such wares. Mortuary remains furthermore suggest that access to these vessels was by no means restricted by social rank (Hung 2011: 237-8), suggesting that the communities who used these wares may not have been strongly stratified (Allard, 2001).

In contrast, for the early Bronze Age sites where Qijia-style wares were found, there is no clear evidence for short- or long-distance exchange of ceramic wares, but some graves contain a limited number of metal and jade objects pointing to long-distance exchange networks among a small subsection of the societies in question (Womack, 2017: 237). The ceramics in both graves and settlements are comparatively plain, and yet, similar forms appear over a relatively large area, though not as large as for the distribution of Majiayao-style painted wares. For both periods, there is robust evidence for a sedentary lifestyle based on millet-dominated agriculture and domesticated animals (esp. pig) (Jia et al., 2013).

For the subsequent period, the middle Bronze Age, hardly anything is known about social structure or subsistence practices of the various communities distinguished by widely differing ceramic traditions. As some graves with Siwa- and Kayue-style ceramics have furnished considerable amounts of bronze items while others held none, it has been suggested that distribution of wealth and status was uneven, while no similar evidence can be quoted for graves with Xindian-style wares (Mao et al. 2014; Pak, 1995; Shui, 2001). Considering the small number of sites that these claims are based on, however, these results can at best be seen as preliminary. The same applies to suggestions for a shift to a pastoral economy for some or all of these groups due to climate change (An et al., 2005; Wu and Liu, 2004). These sweeping claims based on environmental modelling are contradicted by the - admittedly rather sparse - zooarchaeological and palaeobotanical evidence. Some sites with Xindian-type ceramics show evidence for settled farming, others for hunting activities, others again for a strong reliance on sheep rearing (Shui, 2001). For sites associated with Kayue- or Siwa-style wares, a combination of animal herding and millet-based agriculture seems to have been common, but again with a varying importance of the different food sources by site (Pak, 1995: 292-317; Shui, 2001). While for the Hexi corridor and various parts of northern China, recent stable isotope research on human bones has helped immensely in reconstructing ancient diets (e.g., Atahan et al., 2011), no similar material is available for sites containing the types of ceramics discussed here. Likewise, very little faunal or floral evidence is available, simply because many of the sites in question have been excavated decades before environmental sampling became international standard. Thus, further excavation is necessary before more definite suggestions on the social structure and subsistence systems of these communities in question can be made.

As fieldwork, especially on the scale needed here, takes considerable resources, it will take time before we gain deeper insights into the life of the groups in question through that avenue. What is already abundantly available, however, is ceramic material, so this is our chosen dataset for this paper. Most research to date has focused on typochronologies and explanatory models for the connections between the consumers of wares of the same style, while very little attention has been paid to the producers and their craft. Ceramics make up a particular kind of objects whose form, material composition, and traces of craftsmanship combined with their distribution in time 
and space can throw light on the organization of production and handicraft traditions, as well as their transmission over time and space. When viewed in context, research on ceramic production traditions furthermore provides insights into the embeddedness of these processes in the local environment as well as in social structures.

The present project therefore provides a novel perspective on the cultural developments in prehistoric northwest China. Rather than a focus on burial customs, subsistence systems, or form typology alone, we study the craft-technological relationships in the prehistoric pottery from the region as an embedded expression of past human communities, their actions and interactions both with each other and the environment. To achieve this we use a combination of scientific techniques..

A question of this magnitude applied to an area as extensive as northwest China and a period stretching from c. 3300 to 1000 BC can only be addressed through long-term international collaboration, an undertaking which is under way between the University of Oxford, Stockholm University, the Museum of Far Eastern Antiquities (MFEA) in Stockholm, the Gansu Provincial Institute of Archaeology, and Beijing University. As a pilot project, we began with an understudied collection, the early Chinese ceramics excavated by Johan Gunnar Andersson in the 1920 in Gansu, part of which are now held in the MFEA.

As described above, so far ceramic analyses of this material are few, and scientific analysis of ceramics is not well established anywhere in China. While portable X-ray fluorescence (P-ED$\mathrm{XRF}$ ) analysis has been employed on occasion, thin-section analysis is not commonly applied to material from anywhere in China, let alone prehistoric ceramics from the loess plateau, so this pilot study aims to ascertain whether this is a viable approach to this specific body of material.

It has been argued before that thin-section analysis identifying mineralogy and production details, and chemical analysis providing information on composition and potential origin of raw material sources supplement each other ideally (e.g., Vince et al., 2016); however, relatively few studies from around the world have combined these two approaches (for one exception see Papmehl-Dufay et al., 2013). One aim of the study was thus to further test the usefulness of the combination of two otherwise well-known methods of analysis - thin-section petrography and portable X-ray fluorescence (P-ED-XRF) analysis - both in general and for this specific set of material and research questions prior to embarking on a multi-year study of material both from the MFEA and from recent excavations in northwest China. This double aim thus makes this study relevant to both to ceramic specialists world-wide and China-archaeologists in particular.

\section{Material and methods}

The collection in the MFEA is the product of the earliest archaeological excavations conducted in China by the Swedish geologist Johan Gunnar Andersson (Andersson, 1943; Fiskesjö, 2014). Due to a lack of familiarity with the Swedish language by China experts and the absence of Chinese archaeology as a field at Swedish research institutions, the material has remained largely unexplored since the 1940s. Furthermore, because of the early date of excavation, the stratigraphic context of most of the finds is unclear. The re-excavation in recent years of several of the sites 
Andersson discovered now provides comparative material that enables us to place the finds held in Stockholm in their chronological, spatial, and cultural context (Womack et al., 2017).

Among the Stockholm material, samples for micromorphological analysis via thin section microscopy were chosen from one Neolithic, one early Bronze Age, and one middle Bronze Age site choosing locations which are currently under renewed fieldwork, i.e., Majiayao, Qijiaping, and Xindian (Fig. 1). We sampled wares from all periods to identify changes over time and aimed to cover the whole range of past types as far as macroscopically observable. To assess homogeneity in the principles of raw material selection and processing within the same ceramic style, Majiayaostyle painted pottery from three separate sites in the Tao River Valley that are currently undergoing renewed fieldwork - Majiayao, Siwashan, and Xindian - were chosen to be analyzed with P-EDXRF. In both cases, we chose material from recently re-excavated sites to assure a secure grasp of chronology and typological development and make sure that the chosen samples did indeed date to the targeted period.

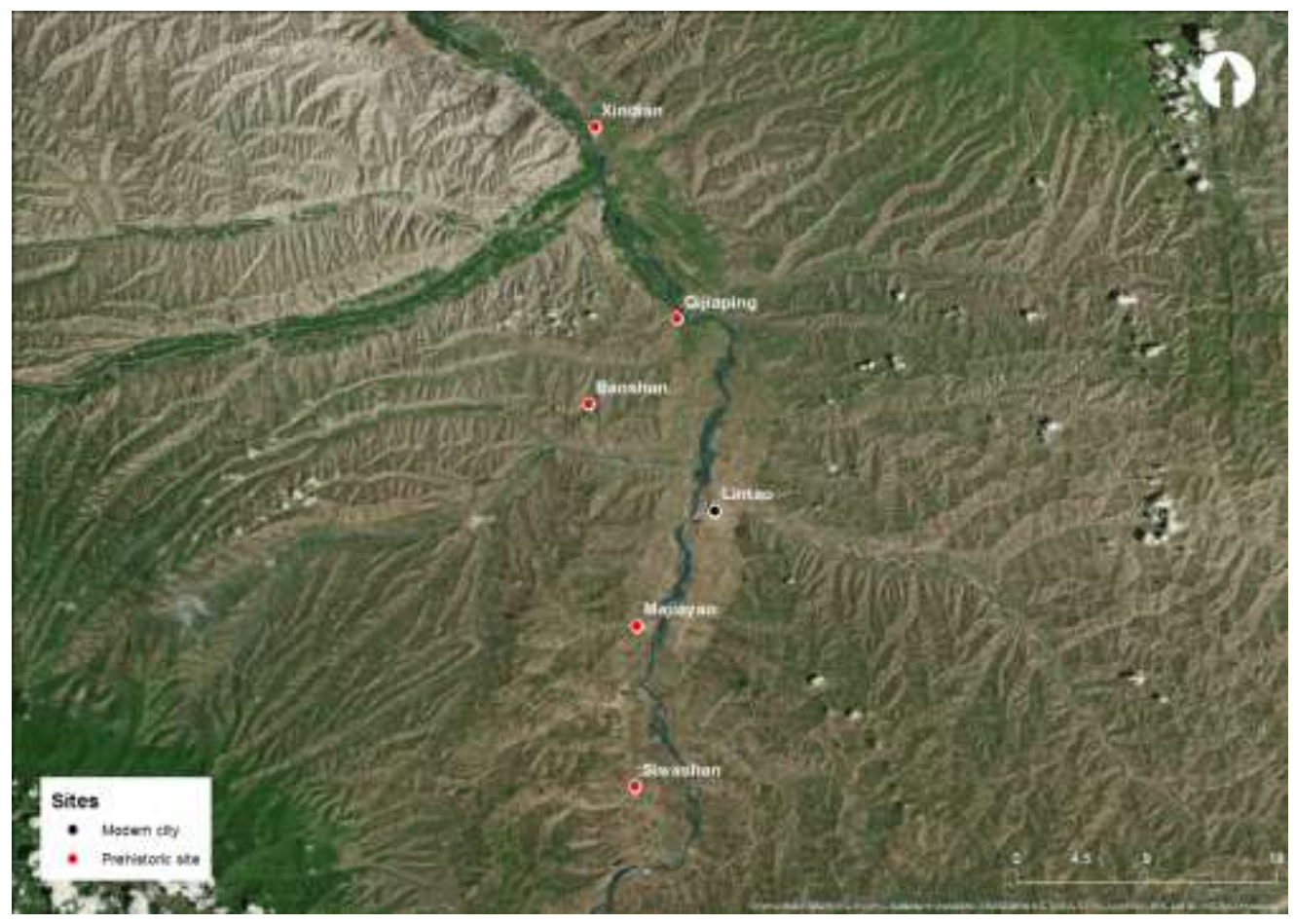

Fig. 1. Location of sites mentioned in the text.

\subsection{Thin-section petrography}

\subsubsection{Method}

Thin section studies are relatively uncommon in Chinese archaeology, with only a handful conducted for all periods of Chinese history, most of them published over the last few years (e.g., Bylin-Althin, 1946; small portions of the PhD dissertation by Lin, 2013; Quinn et al., 2017; Stoltman et al., 2009 and 2018; Womack, 2017). Increasingly more studies instead rely exclusively on chemical analysis (Hung, 2011; Hong et al., 2011 and 2012; criticized by Ren et al., 2013), which has proven to be problematic for ceramics research, as raw material preparation - especially 
tempering or removing inclusions - changes the chemistry of the resultant wares. Petrographic thin section analysis may help identify levigation, tempering, and/or other production techniques that influence the composition of the material.

Thin-section studies are often restricted to a mineralogical description of the ceramics' components and identification of temper (e.g., Lin, 2013; Womack, 2017). However, the ware retains additional data on the production process, such as raw material preparation and building techniques, which may be used to reconstruct the production process and study and distinguish different potting traditions. This approach of focusing on the craft aspects of the ware as seen in thin sections has been promoted primarily by the former Laboratory for Ceramics Research, Lund University, by, among others, one of the authors of the present paper (Asplund and Stilborg, 2013; Hulthén, 1977; Nössler and Stilborg, 2010, Stilborg, 2012 and 2017). In the present paper, we are paying particular attention to any indicators for raw-material preparation such as levigation or mixing of several clays. The identification of forming techniques is more problematic, however, and requires the comparative analysis of a larger number of samples, preferably with two samples - one cut on the horizontal and another perpendicular - to distinguish between coil-building, slabbuilding, and wheel-throwing (Quinn, 2013: 174-181; Ther, 2016; Woods, 1984). Radiographic analysis of complete vessels can provide even deeper insights into the forming process (La Duc and Chang, 2017). This aspect of production will be investigated in future multi-method research analyses of a larger sample of both sherds and complete vessels.

Combining insights into raw material choice, processing, and ideally, forming and firing techniques allows for the identification of different technological traditions and potential points of contact between them that might have led to the transferral of knowledge (Bērziņš, 2008: 219-220; Smith, 2016; Stilborg, 2017). The question of the production organisation (house hold work, professional workshops, or industrial-style production) is also dependant on a more complex understanding of craft traditions and the use of resources, both in terms of raw materials and man power (Peacock, 1982). Having identified different traditions separated by time or space, we look for potential points of contact between them while relating in a more complex way to the human use of resources. To address questions that concern trade and other forms of exchange, more samples, both ceramic and geological, are needed. In this study, we therefore focus on identifying the presence/absence and composition of added temper and also make some suggestions as to underlying principles of raw material choice in order to get an overview of the basic parts of the craft technologies involved in making the sample objects and refine our research questions.

Thin sections $-0.03 \mathrm{~mm}$ thick slices of the wares mounted on object glasses - were studied under a petrographic microscope at magnifications between $\mathrm{x} 20$ and $\mathrm{x} 600$. This method enables an estimation of the coarseness of the clay (i.e. content of non-plastics), the content of calcium, mica, and iron oxide, and the determination of accessory minerals like ore and various dark minerals (e.g., Quinn, 2013). Based on the knowledge of the composition of the raw clay, added temper may be discerned either as a material foreign to the raw clay or as a deviant grain size fraction. In a particularly well-homogenized ware, it may be difficult to distinguish between added fine sand temper and natural inclusions. However, a clear break in the grain size distribution will, in most cases, signal added temper (Quinn, 2013: 156-171). Here, geological sampling can help to establish the natural variability of locally available raw material. Such sampling is currently being conducted 
by Anke Hein in collaboration with Andrew Womack (University of Toronto) to establish a baseline for future petrographic research.

The main types of temper are crushed stone, sand, grog (i.e., crushed ceramic sherds), and various organics. The latter was not observed in samples chosen for this study. A crushed stone temper is identified by a limited range of minerals and repetitive structural characteristics of the rock fragments. A sand temper is usually characterized by a mostly homogenous grain size, i.e., a fair/good sorting. Sorted sands are mostly dominated by quartz, but quartzite and sandstone are also fairly common constituents. Grog temper presents special problems. The visibility of the matrix grains (i.e., the fired clay part of the older crushed sherds used as temper) strongly depends on the difference between the firing temperature of the grog-tempered ware and that of the grogware(s) itself. If the former is clearly higher than the latter, most of the matrix grains will not be discernible in the sample, and thus the estimates of the temper amount will be inaccurate. Secondly, concentrations of iron oxide and clay stone fragments naturally in the clay often share several of the characteristics of added grog grains. Therefore, in order to arrive at a certain determination of grog tempering, an analytical protocol was developed at the Laboratory for Ceramic Research, Lund University (Lindahl, 1990). To be accepted as grog tempering, the grains must be angular to subangular, display cracks around the edges, and have a structure deviating from the surrounding matrix of the grog-tempered ware.

Grog is especially interesting from a craft tradition perspective since secondary grog (i.e., the use of older ceramic materials already containing crushed wares, which, when crushed again, produce grog in grog) reveals continuity in the tempering technology. The composition of the wares used as grog temper in new vessels also facilitates the search for connections to other contemporary or older ceramic traditions, on occasion even demonstrating links with other regions if non-local pots were used (Shepard, 1954: 348-350). We are thus devoting particular attention to the occurrence and nature of grog-tempered wares among the samples at hand.

Having identified added temper, the quality - i.e., the amount and maximum grain size can be estimated and the homogeneity described. For a temper to function properly, it ought to be evenly distributed throughout the ware. Grossly uneven distribution of the temper increases the risk for uneven shrinkage during drying and firing, potentially leading to fatal cracks. Structures in the ware may reveal vessel building techniques, and the even distribution of temper through the clay is a useful parameter for studying the quality of the craftsmanship.

\subsubsection{Sample selection}

A selection of pottery of characteristic form types from the sites of Majiayao, Qijiaping, and Xindian was recorded macroscopically with respect to ware composition decoration and vessel forms. Painted fine wares from Majiayao were largely avoided since their contribution to the discussion of added temper and the complexity of ware composition can be expected to be low. On the basis of this initial recording, 10 sherds were chosen which would represent as broad a variation in technology and vessel type at the three sites as possible. From these 10 sherds, 11 thin sections were produced. We made two thin sections for one sherd because the lower break showed a stone tempered ware, while the upper break revealed no macroscopically visible signs of added temper. 


\subsection{X-Ray Fluorescence Analysis}

\subsubsection{Method}

$\mathrm{X}$-ray fluorescence analysis with the portable equipment s a non-destructive method for chemical and elemental analysis. For the analyses of the sherds from Majiayao, Xindian, Siwashan and Qijiaping, an Olympus Delta 50 portable XRF was used (for methodological and technical issues consult Helfert and Böhme, 2010). The method has highly accurate determinations for major elements. A limitation of XRF analysis with this equipment is that lighter elements from sodium (Na) onward cannot be detected. Tests with similar equipment at the Johann Wolfgang GoetheUniversität Frankfurt have furthermore shown that the variation in the results for magnesium is too high and therefore this element was not included (Helfert, 2013, 32). The elements analysed in this investigation were: Al, Si, P, S, Cl, K, Ca, Ti, V, Cr, Mn, Fe, Co, Ni, Cu, Zn, As, Se, Rb, Sr, Y, Zr, $\mathrm{Nb}, \mathrm{Mo}, \mathrm{Cd}, \mathrm{Sn}, \mathrm{Sb}, \mathrm{Ta}, \mathrm{W}, \mathrm{Hg}, \mathrm{Pb}, \mathrm{Bi}$, Th and $\mathrm{U}$.

Clay, and by default ceramics, consist mainly of the elements Silica (Si) and Aluminium (Al) in the oxide states $\mathrm{SiO} 2$ and $\mathrm{Al} 2 \mathrm{O} 3$ as well as quite a large portion of oxides of Iron ( $\mathrm{Fe} 2 \mathrm{O} 2 / \mathrm{Fe} 2 \mathrm{O} 3)$, Calcium $(\mathrm{CaO})$ and Potassium $(\mathrm{K} 2 \mathrm{O})$. These are all normally found in percentage amounts, while other elements are only detected in parts per million (ppm). All values presented here are given in percentage. A $5 \mathrm{~mm}$ measuring spot was used for analysis. Measuring time was 60 seconds. To improve measurement accuracy, three measurements have been conducted on three fresh, cleaned breaks of each sherd, deliberately avoiding larger inclusions where visible. The mean values of the three value sets were then calculated after eliminating measurements with large deviations. The mean values were used in the statistical analysis using the SPSS package.

Furthermore, in order to be comparable to chemical analyses using other handheld devices or methods (such as LA-ICP-AES), we will calibrate the instrument using ceramic standards. This is done using a method developed by Helfert (2013) at the Goethe-Universität Frankfurt. For practical reasons, the calibration has not been conducted, yet, but will be made next year followed by corrections of the results accordingly. For this report of the pilot study, the un-calibrated data are used as the relative accuracy and precision is the same for all measurements taken.

As with all chemical analyses, the results must be thoroughly scrutinized to avoid problems such as potential post-depositional pollution, the effect of added temper, and other possible sources of error or inaccuracy connected with hand-held spot analysis in a non-laboratory environment. So long as these potential issues are kept in mind and balanced out where possible (as will be explained in section 3.2.2), P-ED-XRF measurements provide a good initial overview of a given material, since a large sample may be analysed with comparably little effort. The larger sample also counteracts the lower accuracy of the P-ED-XRF method compared to other conventional methods such as ICP-MS and LA-ICP-AES. The critique most often raised against P-ED-XRF concerns analysing non-homogenous materials (e.g., a tempered ware) (Mecking et al., 2013, 56). Practical tests have shown, however, that it does not pose a major problem (Helfert, 2013) - especially not if the goal is to get an overview of the variation rather than making an exact determination of provenance. For the latter, the conventional methods are preferred. 


\subsubsection{Sample selection}

To assess differences in raw material choice and processing, samples were chosen from four separate sites within the same drainage system, the Tao River Valley to ensure a similar geological environment and thus - at least theoretically - access to the same kinds of raw material. The focus was on Majiayao-type Neolithic fine ware from the sites of Majiayao (22 samples), Siwashan (11 samples), and Xindian (9 samples). Additional measurements were taken on the coarse-ware samples chosen for thin section analysis (3 samples from Qijiaping, 3 from Xindian, 4 from Majiayao), adding up to 26 Majiayao, 3 Qijiaping, 11 Siwashan, and 12 Xindian samples, a total of 52 samples, 46 of them dating to the Neolithic Majiayao period.

\section{Results}

\subsection{Thin-section petrography}

\subsubsection{Majiayao (TS 7-11; four sherds)}

The clays used for these vessels varied from a finely sorted, calcium rich clay (TS 8) to a coarse, sorted, calciferous clay (Ts 7). None of them appears to have been levigated or mixed from several clays. The varying degree of sorting and the mineralogy characterizes them as secondary clays that were more likely deposited by water than by wind (Appendix A), throwing doubt on the general assumption that clays used for ceramic production in northern China were loess-based. Three of the samples present marked variation: a medium coarse clay with no added temper (Ts 9), a fine clay tempered with a coarse sand (24\% volume, including sandstone, clay schist and other sedimentary rocks, TS 8$)$, and a coarse clay tempered with crushed rock (15\% volume, syenite, Ts 7).

The fourth sample is the sherd (K11998:19) with varying amounts of temper (for full details of the results of the thin section analyses see Appendix A) from which Ts 10 and Ts 11 were taken. The ware of this large sherd is divided into a lower, tempered part with a coarse, cord-marked surface and an upper, apparently un-tempered part with a burnished, painted surface - so in reality a hybrid of coarse and fine ware. This made it necessary to make thin sections of both parts. Normally, an essential prerequisite for a successful drying and firing of a ceramic vessel is - besides a fairly even wall thickness - an even spread of the non-plastics in the ware. This secures an even shrinkage when the pore water of the clay evaporates during drying and the initial phase of firing, but also helps during later stages of firing when the crystal water is released from the deconstructed clay crystals and ceramic crystals are formed. The part of the sampled sherd that represents the upper, burnished part of the vessel decorated with two horizontal painted black lines is made from a fine, sorted, iron rich, calciferous clay. A third of the sample, which was made from an almost vertical cut, ${ }^{1}$ contains $7 \%$ (volume) of crushed rock (syenite, max. grain size $1.8 \mathrm{~mm}$ ), while two thirds contain no rock fragments and are thus un-tempered. The tempered part represents a lower part of the vessel than the un-tempered part. The "last" observable temper grain - visible when moving upwards in the vessel wall - lies just at the lower edge of the lowest of the black painted lines on the surface (Fig. 2). The ware of the lower thin section (Ts 11), taken from below an angle

\footnotetext{
${ }^{1}$ The cut of a sample for thin section is traditionally made vertically in relation to the vessel wall. This is done in order to study traces from the vessel building technology.
} 
in the vessel profile where the surface is cord-marked, is clearly different. The clay is the same but tempered with $10 \%$ (volume) crushed rock with a maximum grain size of $4.3 \mathrm{~mm}$. The rock is the same as in Ts 10 but the sorting appears to be different and the temper grains are fairly well distributed in the ware.

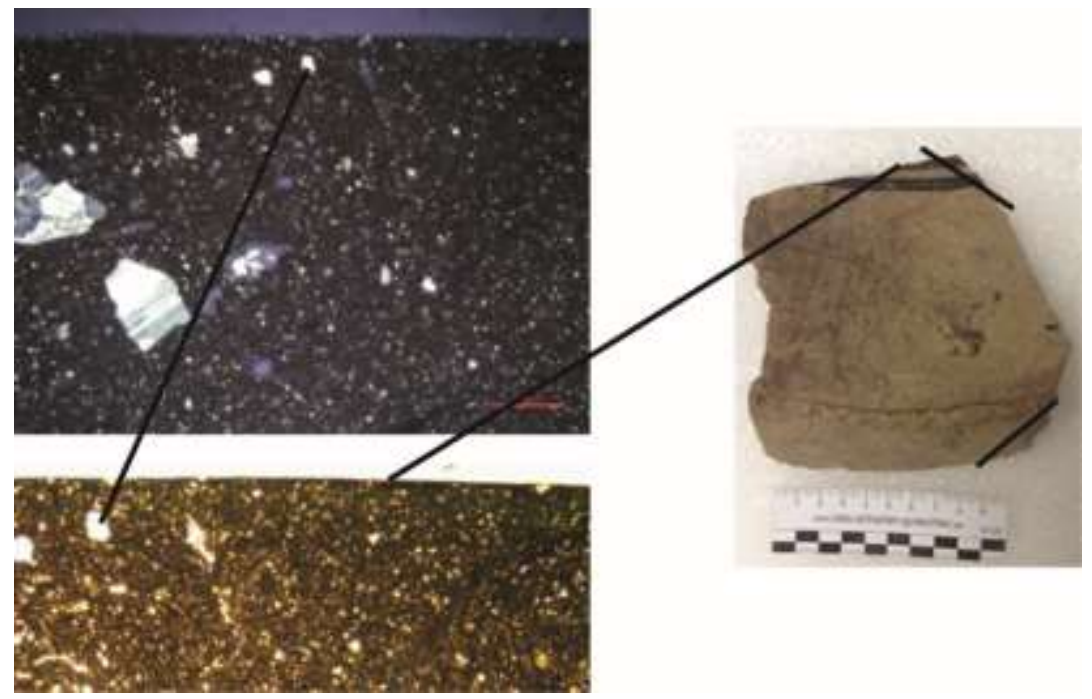

Fig. 2. Microscope photos of Ts 11 (top left xpl; bottom left ppl) where the painted line on the surface is visible (darker) and a photo of the sherd with the situation of the upper sample indicated. The "last" grain of the crushed rock temper (upper line) matches the "start" of the painted area.

This vessel, which in its outer appearance combines a lower coarse ware part having a cordmarked surface with an upper fine ware part (burnished and with painted decorations), has an internal counterpart in the ware composition - coarsely crushed rock temper in the lower part and fine clay without added temper in the painted upper part. In between, the vessel wall appears to be rock tempered with a similar amount of rock but more finely crushed, possibly to facilitate the burnishing of the surface. Such composite wares defy what is normally seen in good craftmanship as different parts of the vessel react differently to temperature changes during firing, introducing a greater risk of vessel failure. This risk could be reduced by controlled conditions both in drying and firing, adding to the effort invested in making this vessel. The varied temper appears to be a very deliberate and conscious technological choice, which has been confirmed in later recordings of other vessels with the same combinations of complex outer and inner design in the MFEA collections. This suggests that fine-wares and coarse-wares were made in the same production unit or two units springing from exactly the same tradition and using the same raw materials. This special ware requires a high level of control of all aspects of the production process including: choosing the raw material; adding the right amount of temper to secure the integrity of the vessel while providing upper and lower part with different characteristics; preparing and applying the paint in a way that would survive the firing process; and tightly controlling the kiln temperature and atmosphere to prevent this complex structure from failing during firing or cooling. That such a vessel could be successfully created is evidence of a high level of craftsmanship. 


\subsubsection{Qijiaping (Ts 4-6)}

The clays used for these vessels varied from a fine, sorted, calcium rich clay (Ts 5) to a coarse, sorted, calciferous clay (Ts 6). None of the clays appear to have been levigated or mixed from several clays. The varying degree of sorting and the mineralogy characterizes them as secondary clays that were more likely deposited by water than by wind (Appendix A). The three samples belong to two types: fine clay tempered with sand (Ts 4-5, $10 \%$ volume including sandstone, chert and quartz) and coarse clay tempered with crushed rock (Ts 6, $17 \%$ volume, syenite).

\subsubsection{Xindian (Ts 1-3)}

The clays used for these three vessels vary from a medium-coarse, sorted, calciferous clay (Ts 1) to a coarse, unsorted, calcium rich clay (Ts 2). None of the clays appears to have been levigated or mixed from several clays. The varying degree of sorting and the mineralogy characterizes them as secondary clays that were more likely deposited by water than by wind. One of the samples (Ts 1) consists of a medium coarse clay tempered with crushed rock (granite, $11 \%$ volume) with resemblance to the rock-tempered type found in the materials from Majiayao and Qijiaping. The two other samples represent a decidedly different ware type characterized by grog tempering.

The ware for the vessel Ts 2 is tempered with ca. 6\% (volume) grog (max grain $2.3 \mathrm{~mm}$ ), while the ware of the vessel Ts 3 is tempered with ca 14\% (volume) grog (max grain $3 \mathrm{~mm}$ ). As mentioned above, the estimation of the amount of grog temper is difficult. The grog consists of grains from 2-3 different ware types and in Ts 3 there is even a number of grains that contain secondary grog grains. That means that the temper derived from a mixed collection of crushed sherds originating from a range of different pots - all of which in turn seem to have been grogtempered. The latter is most clearly shown by the secondary grog - i.e. an earlier generation of grog temper. This kind of grog temper with several different ware types and secondary grog documents a long tradition of grog tempering. Not only do we see earlier generations of grogtempered wares, the variation in wares among the grog tells us that the mix of grog-grains from several different vessels had become a temper raw material in its own right being topped up with any old crushed sherd whenever the amount of raw material was dwindling. This is in contrast with a more basic use of grog tempering where the temper material was procured by crushing a sufficiently large piece of one older pot (very often not grog-tempered). The advanced grog tempering of Ts 2 and 3 thus presents an established craft tradition.

What is less clear are the reasons for the use of grog temper. Grog temper reduces shrinkage, can inhibit the propagation of cracks throughout the material (though less effectively than crushed rock or sand temper), and produces a lighter vessel than rock temper (Bronitsky and Hamer, 1986). Nevertheless, the resultant material is more prone to breakage on physical or thermal impact, making it less ideal for cooking vessels. The emergence and continuation of a tradition of grogtempering among some potting communities in Northwest China thus requires further thought and research. 


\subsection{P-ED-XRF analysis}

\subsubsection{Results}

A number of minerals could be measured only on a small number of samples and were thus excluded in the subsequent statistical analysis (Appendix B). The excluded elements are S, Mo, $\mathrm{Hg}, \mathrm{Bi}, \mathrm{U}, \mathrm{P}, \mathrm{V}, \mathrm{Cr}, \mathrm{Ni}, \mathrm{Cu}, \mathrm{As}$, and Th. All analyses were conducted based on the measured values for Al, Si, K, Ca, Ti, Mn, Fe, Zn, Rb, Sr, Y, Zr, Nb, Nb, Mo, Ta, and Pb.

Regression factor analysis shows that the main elements contributing to the variation are Al, Si, K, Ca, Ti, Mn, and Fe (Tab. 1; Fig. 3). The dominant importance of the main elements for the spread is supported by a very similar spread in the bivariate Al-Si-diagram (Fig. 4). In both cases, there is a clear overlap in the results from the four main sites.

Tab. 1. Results of the Principle Component Analysis

\section{Component matrix ${ }^{a}$}

\begin{tabular}{|c|c|c|c|}
\hline & & ponents & \\
\hline & 1 & 2 & 3 \\
\hline $\mathrm{Al}$ & 893 & 158 & ,035 \\
\hline $\mathrm{Si}$ & ,000 & ,895 &,- 125 \\
\hline K & ,654 & ,359 &,- 352 \\
\hline $\mathrm{Ca}$ & -,258 &,- 715 &,- 423 \\
\hline $\mathrm{Ti}$ & ,764 & ,320 & ,094 \\
\hline $\mathrm{Mn}$ & , 145 &,- 369 & 872 \\
\hline $\mathrm{Fe}$ & 917 &,- 137 & ,113 \\
\hline $\mathrm{Rb}$ & ,928 &,- 105 & ,013 \\
\hline $\mathrm{Sr}$ & ,255 &,- 557 &,- 108 \\
\hline Y & ,626 &,- 303 &,- 238 \\
\hline $\mathrm{Zr}$ & -,296 & ,666 & , 159 \\
\hline
\end{tabular}

Extraction method: main component analysis.

a. 3 components extracted 


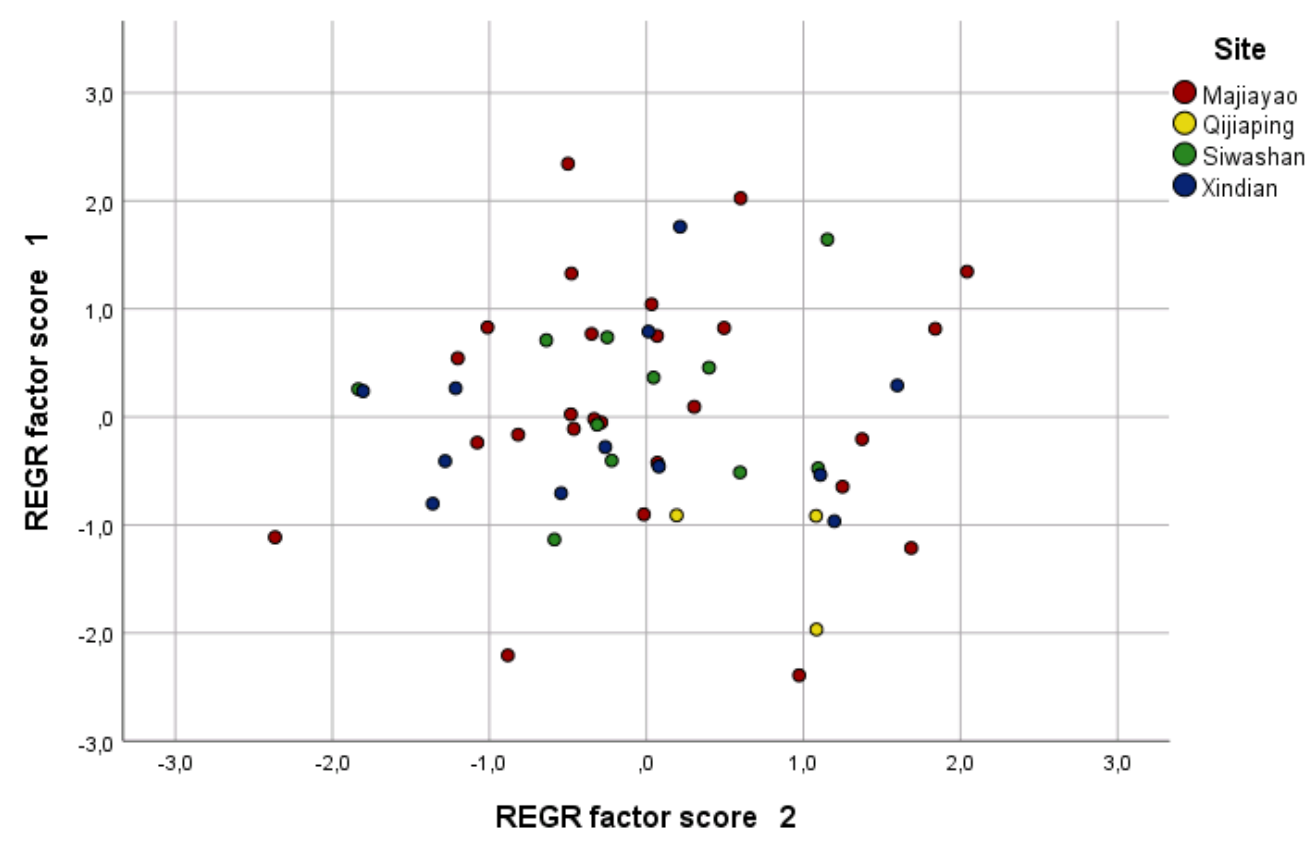

Fig. 3. Principal Component Analysis scores 1 and 2.

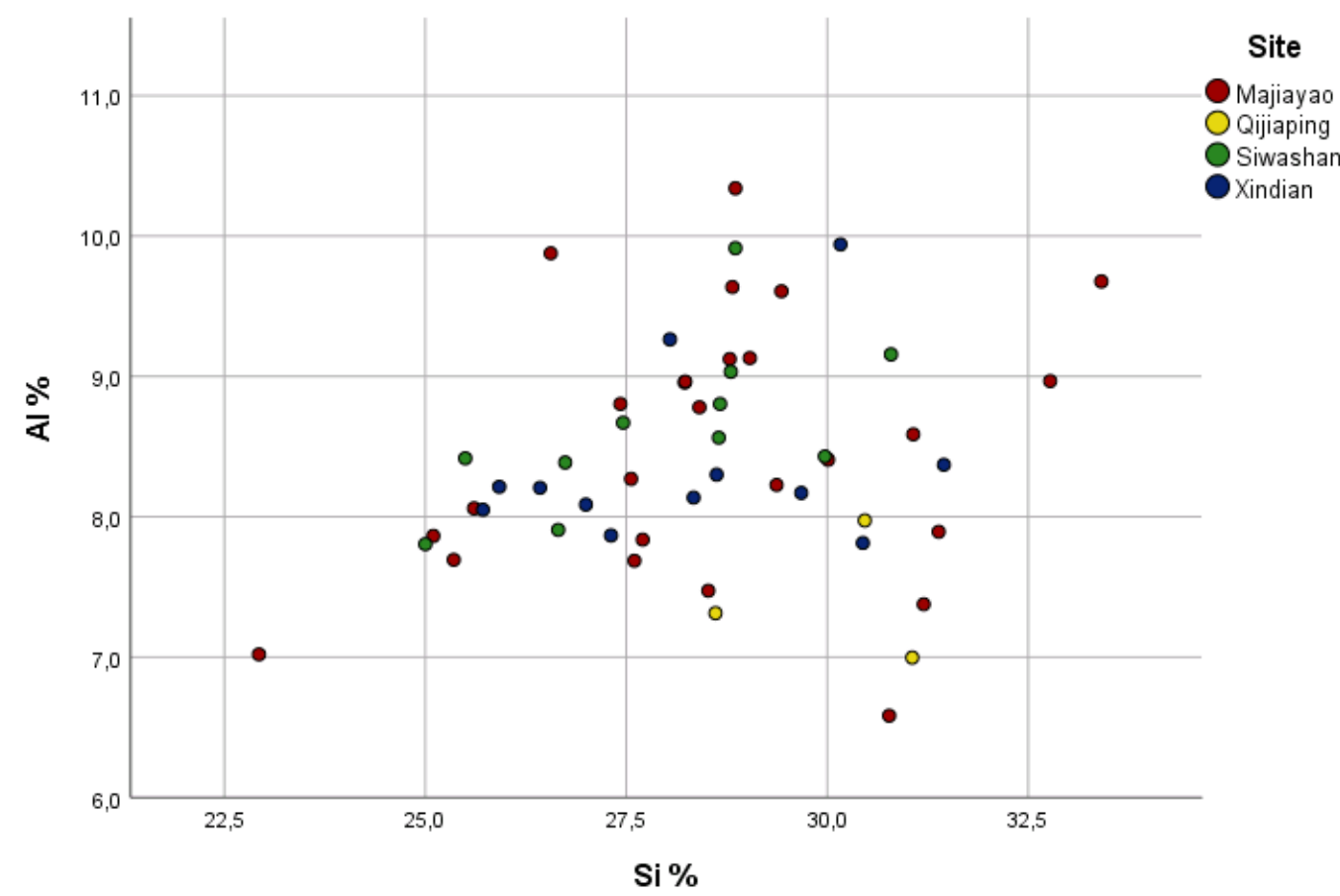

Fig. 4. Comparison of aluminium and silicate content of the ceramic samples colour-marked based on site.

Larger variation is visible among the samples from the Majiayao site compared to samples from Siwashan and Xindian. Since the majority of the samples analyzed date to the Majiayao period, this great spread is unlikely to be the result of temporal changes over time but seems to reflect a larger variation in the clay qualities at the Majiayao site in particular, indicating either a 
wider range of ceramic sources (clay and temper) or a larger number of potters involved in the production of the ceramics in question. This difference merits further investigation.

No particularly clear correlation between object type, decoration type, or ware color and overall chemical composition is discernible. There is a tendency, however, for basins and bowls to be lower in silicate (i.e., "finer" in appearance with lower silt/sand contents and higher proportions of fine clay particles) and higher in aluminum (the latter leading to higher strength, hardness, wear resistance, and temperature stability) (Hamer and Hamer, 2003; Mhanicka, 2012) (Fig. 5). Both vessel types generally have thinner walls, are more highly burnished, and more strongly sintered, all characteristics to which higher aluminum and lower silicate content are conducive. All of these properties as well as the paint applied to most of them furthermore suggest greater time and resource investment, indicating a special function or meaning attached to these items. It has to be kept in mind, though, that the determination of vessel forms is tentative, as no complete vessels but only small sherds were available. The question of differences in raw material choice based on ceramic form thus merits further non-destructive investigation with the help of P-ED-XRF and the analysis of complete or nearly-complete vessels. As this relates to main elements, pollution and detection limits for trace elements with P-ED-XRF will not be a problem.

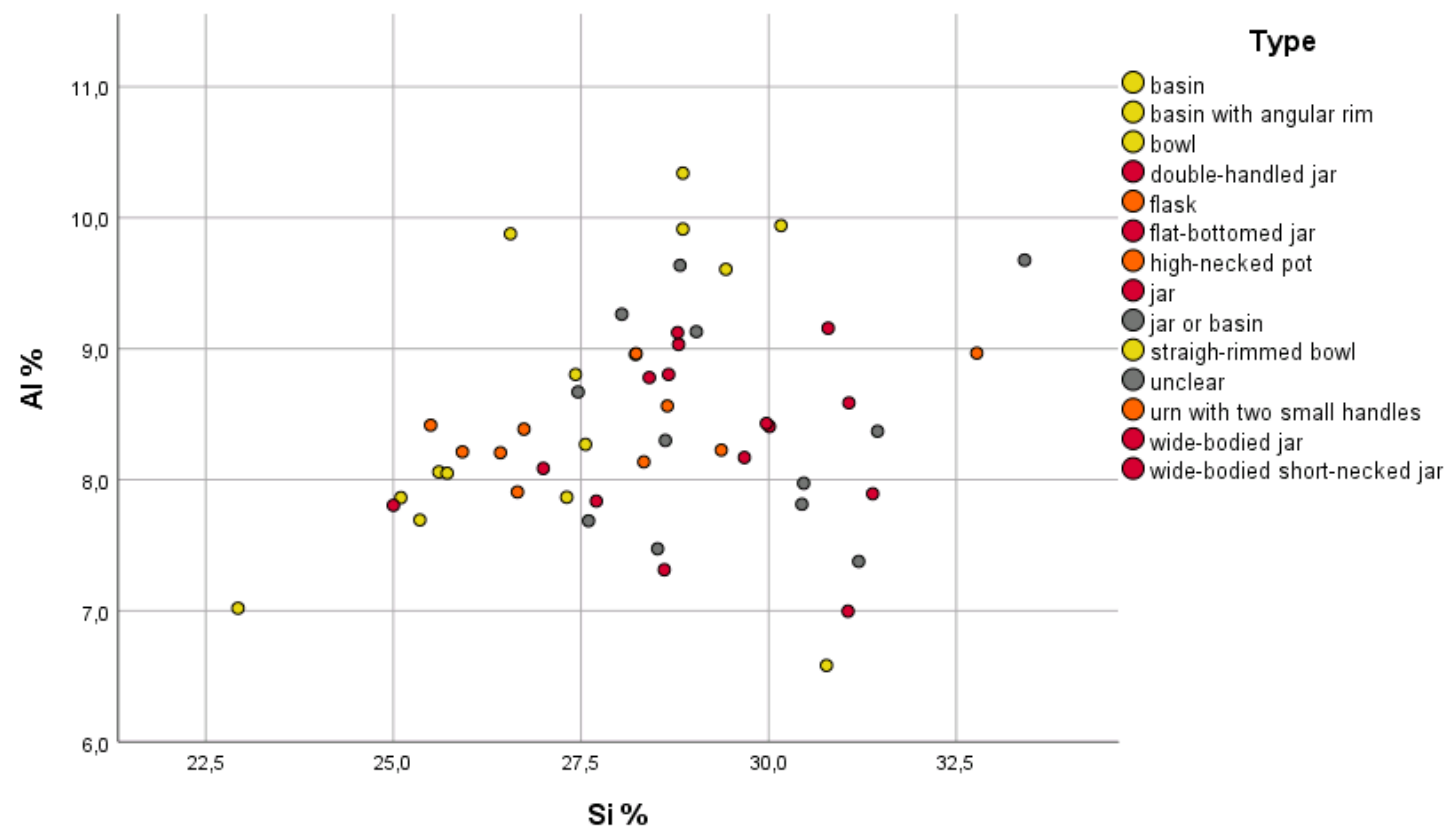

Fig. 5. Al and Si content by ceramic form categories (bowls and basins colored yellow, jars red, pots, urns, and flask orange).

The thin sectioned tempered wares do not deviate markedly in chemical composition from the non-tempered samples with the exception for a bias towards higher silica content as would be expected (Fig. 6-7). The clay used for tempered and un-tempered wares thus seems to be the same from both Neolithic and Bronze Age sites considered here. 


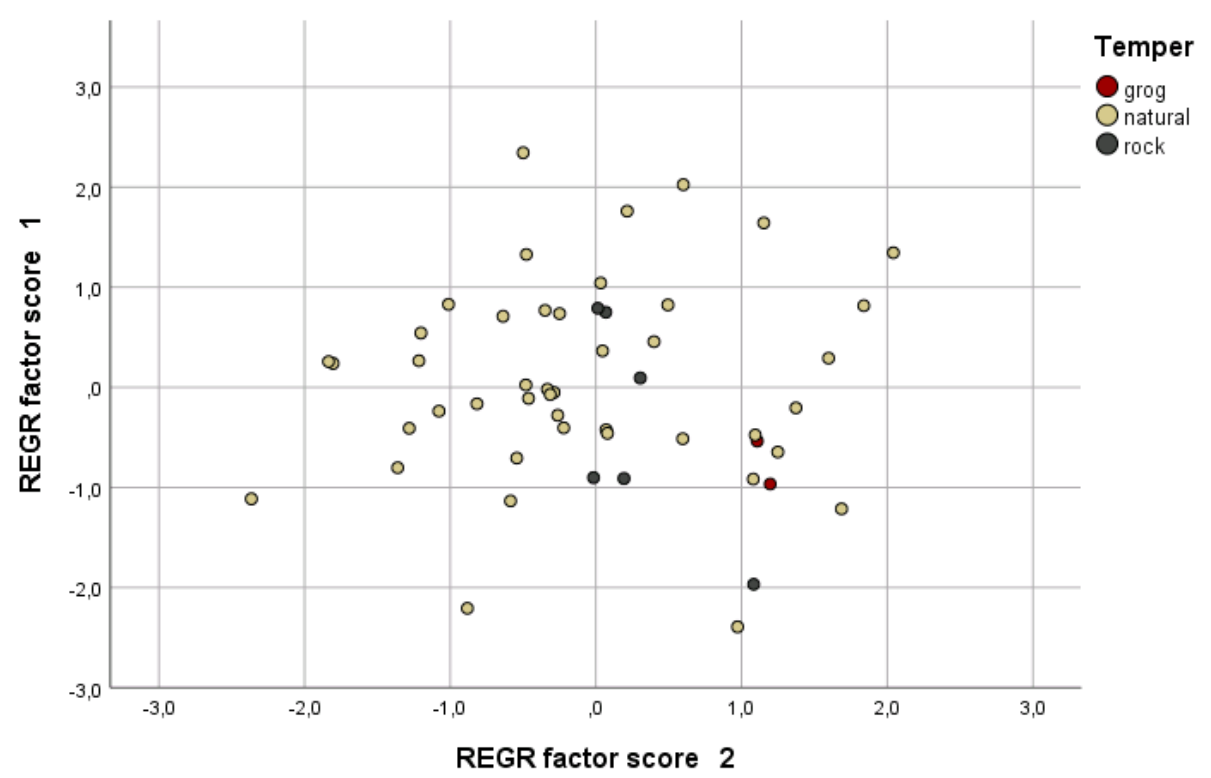

Fig. 6. Factors 1 and 2 by temper type.

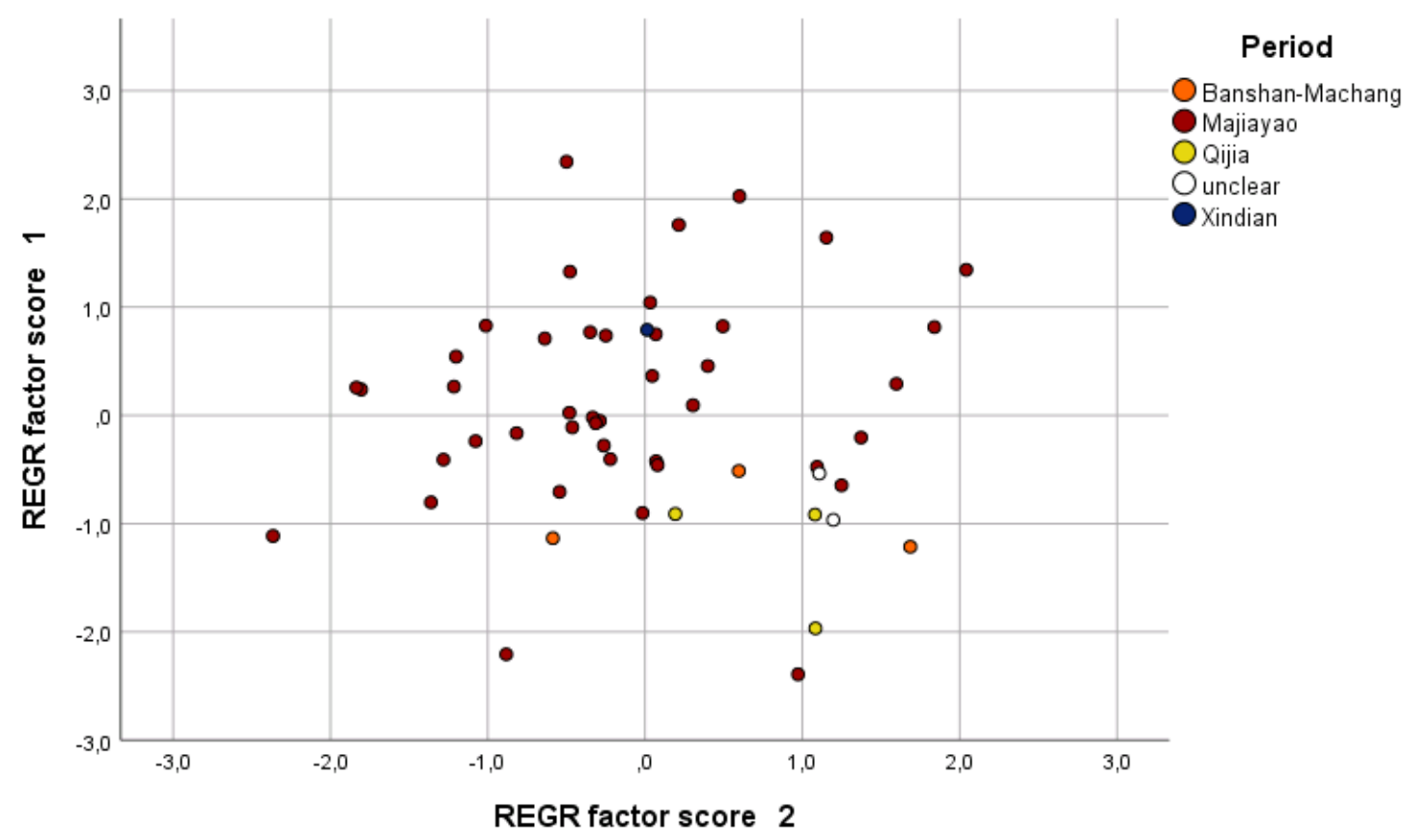

Fig. 7. Factors 1 and 2 by period.

A check for the homogeneity of the material is looking at the correlation between Rubidium $(\mathrm{Rb})$ and Potassium $(\mathrm{K})$. The more the samples fall within one positively correlated swarm, the more homogenous the material (Salminen, 2006). Such diagrams (Fig. 8-9) show positive correlations for all three materials and the trend lines suggest that the samples from Xindian and Siwashan are more similar to each other than to the material from Majiayao. The reason could be 
the larger overall variation in the Majiayao material pointed out above. The very different correlation for the Qijiaping samples is almost certainly due to the small number of samples.

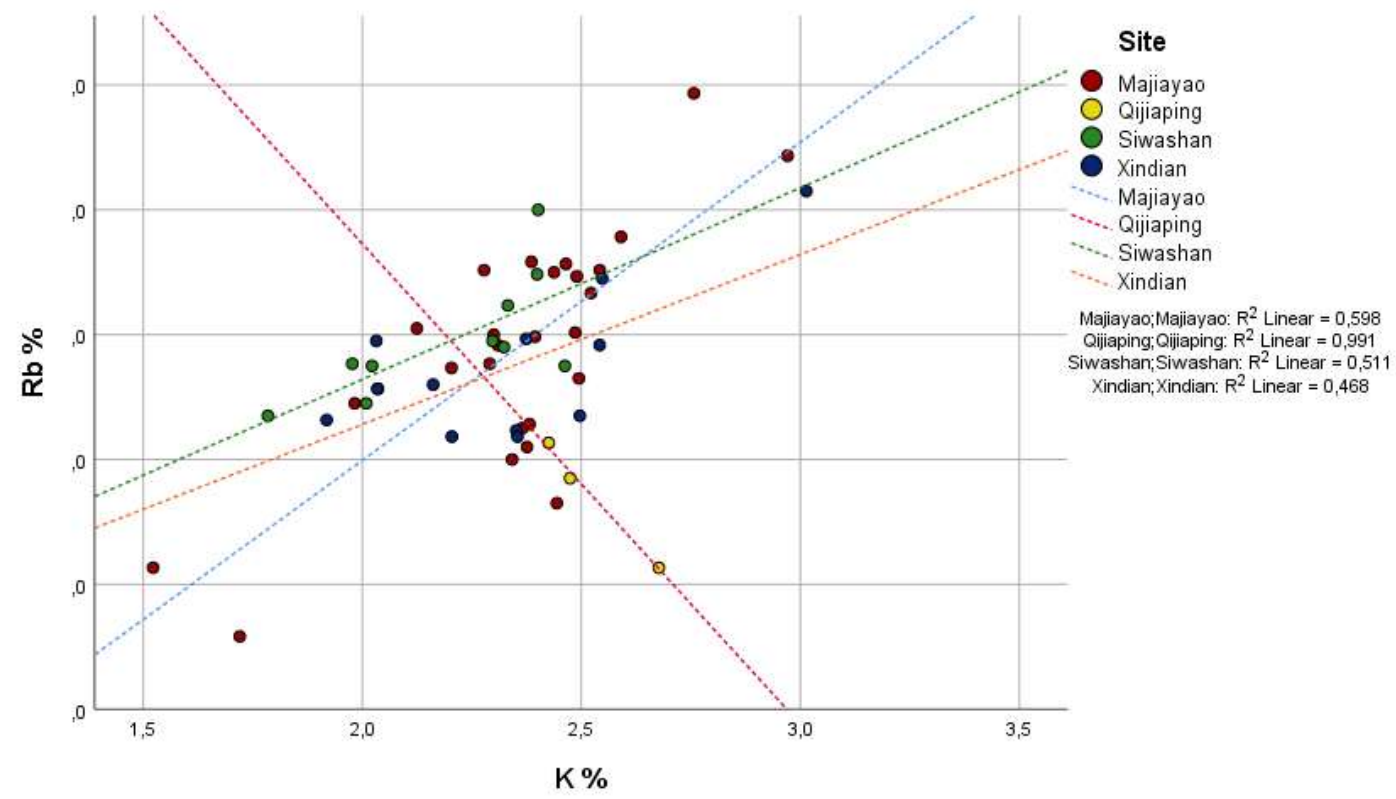

Fig. 8. Rb vs. K content by site.

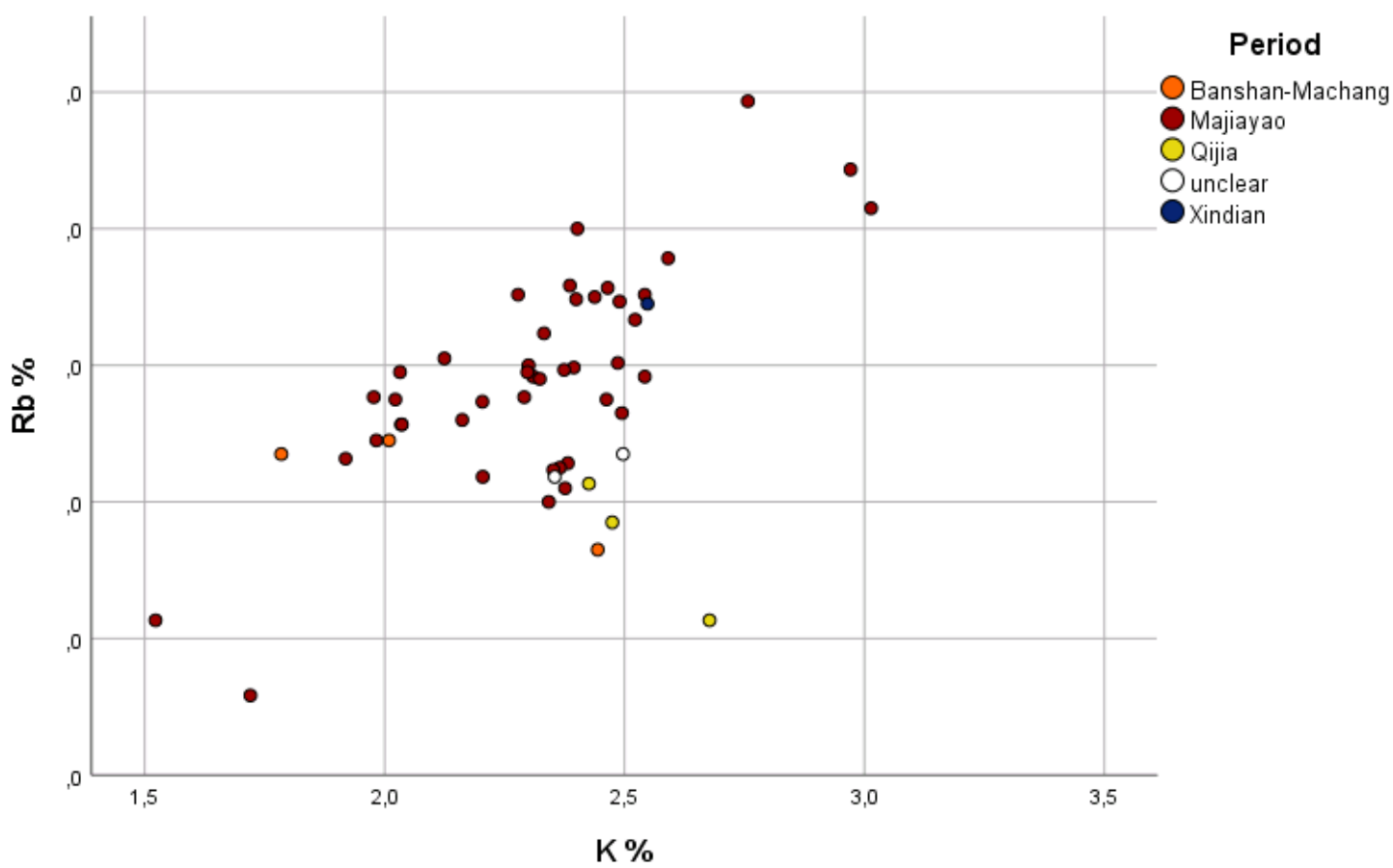

Fig. 9. Rb vs K content by period.

\subsubsection{Issues of sample pollution}

A potential problem for chemical analyses is the possibility of chemical pollution from dissolved materials in the deposition matrix (or use environment) entering cracks in the sherd or 
being absorbed by the porous ware. Calcium, metal oxides, phosphor, sulphur, and barium are wellknown potential pollutants. In some cases - such as calcium penetrating the sherd - the pollution is visible in the thin section and indeed deposits on the surfaces and breakages of the sherds could be a clear warning that the chemical signature of the ware is compromised by post-depositional alterations. As a consequence, in one of the wares examined by thin sectioning from this study (TS 4; K11242:665, Qijiaping) the calcium content may well be from secondary pollution.

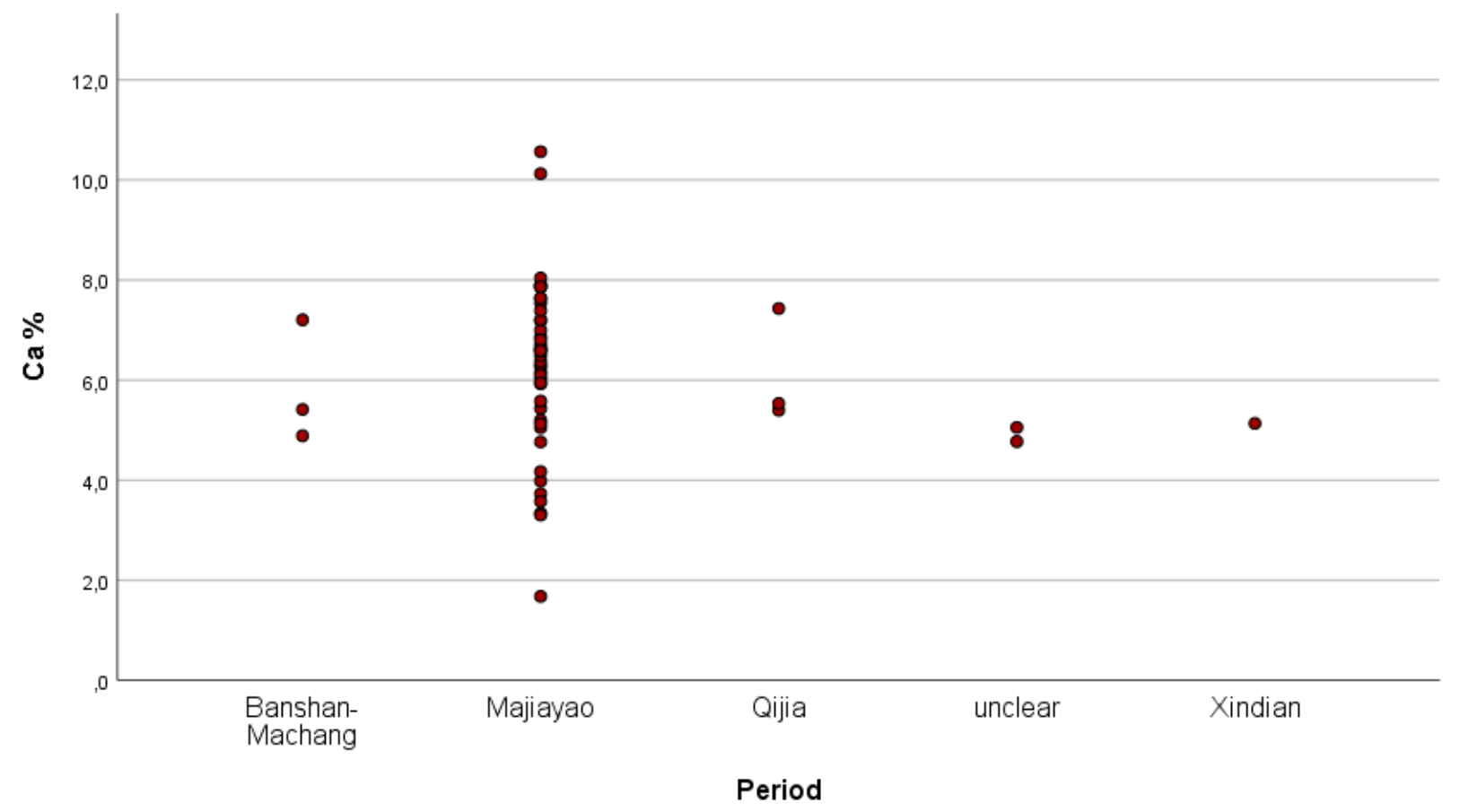

Fig. 10. Ca percentage per sample by site.

As mentioned above, the occurrence of calcium pollution is known, but since clays in this area are generally calciferous it does not pose a major problem. Nevertheless, samples with particularly high calcium contents - as seen in some cases here - merit special attention (Fig. 10). Variations in the content of $\mathrm{Ca}$ were noted and contents over $0.03 \%$ occurred in ten of the samples from Majiayao, seven of the samples from Xindian, and six of the samples from Siwashan. Some of these readings could be the result of pollution.

\section{Discussion}

\subsection{Results of the thin-section petrography}

The clays used as raw material for the vessels in this study vary considerably in coarseness and sorting. The mineralogy of non-plastics is less varied, and all clays contain calcium. The amount of calcium and its distribution in the clay fluctuates markedly. This variation would have had a strong impact on the firing behavior of the wares. All the calcium is fine grained and the risk of lime-spalling is therefore not a major problem. At higher temperatures, however, the calcium will act as a strong flux, lowering the temperature at which ceramics start to smelt, shortening the sintering interval, and thereby introducing a risk for deformation (Worrall, 1986: $220 \mathrm{ff}$.). The best 
way to avoid this is to fire below the sintering temperature (most often between $900^{\circ}$ and $1,000^{\circ} \mathrm{C}$ ); indeed, the optical properties ${ }^{2}$ of the fired wares under the polarizing microscope indicate firing temperatures not much higher than $700^{\circ} \mathrm{C}$.

In our petrographic analyses, tempered wares were prioritized in the sample since a primary objective was to establish the existence and character of tempering as a phenomenon and because the higher complexity of tempered wares provided us with a better chance of identifying different craft traditions (e.g., Quinn, 2013; Stilborg, 2017). Only one sample showed naturally coarse material while all others contained added temper. Wares tempered with crushed rock (granite/syenite) appear on all three sites, sand temper at Majiayao and Qijiaping, and grog temper so far only at Xindian. The temper quality (temper volume in relation to maximum grain size) is an important part of the craft and often of the craft tradition (Asplund and Stilborg, 2013; Nössler and Stilborg, 2010; Shepard, 1954). We have already noted some variation, but a larger sample size is needed to reach statistical significance.

The complex coarse/fine ware vessel (Majiayao Ts 10-11) with matching paint on the outside of the fine part and a roughed surface on the coarse parts more likely represents a deliberate choice based on unclear cultural/aesthetic reasons than a technologically sound way of making pottery. It shows that - at least at Majiayao - there was a conscious division between fine ware and coarse ware, one being naturally coarse with a burnished, often painted surface and the other with a cord-marked surface on a rock tempered ware. This classification seems clear and to join the two in one pot must be significant. What it means is more difficult to assess, but the existence of this peculiar vessel does inform us that both types of ware were made by the same workshop or workshop tradition.

The coarse temper of the thin-walled, highly decorated vessel from Qijiaping (Ts 6) is also remarkable. The choice of a coarse temper is technically unnecessary for this thin-walled vessel and makes the construction of the pot more difficult. The potential use as a cooking vessel could be a practical reason for including the coarse rock temper, but complex decorations are unusual on utensils for daily cooking. The fine decoration may point to a special kind of cooking, be it in a special context (e.g., ritual, feasting) or for cooking a special type of food imbued with ritual or religious meaning. As this type of vessel is extremely rare and mostly occurs in burials, a ritual context of usage is not unlikely.

The grog temper in the two Xindian samples stands out most starkly from the overall sample, not only because it was not observed at the other two sites but also because it seems to represent a technological tradition with a longer history the sources of which are as of yet unclear.

\subsection{Results of the P-ED-XRF analysis}

The most important contribution of the P-ED-XRF analyses lies in an overview of the chemical variation. It has become clear that the clays used for the ceramics found on the sites of Majiayao, Xindian, and Siwashan are largely identical in chemical composition. This result is in

\footnotetext{
${ }^{2}$ Below the sintering temperature the mica and clay crystals will split the polarized light beam resulting in a color in the analyzer under crossed polarized light. Above this temperature the changes in crystal structure will result in most of the polarized light passing through unbroken and unable to pass the analyzer resulting in darkness.
} 
line with the findings of the petrographic analysis of the thin sections. Based on these chemical results, it is impossible to decide whether all Majiayao-phase fine ware was produced in one central location and then traded to other locales or if the similarity in wares exists despite separate production at the three different sites. To resolve this question, a thorough survey and analyses of local clays from Tao River Valley needs to be made, including more advanced chemical analyses to catch differences in trace elements not covered by the measuring scope of the P-ED-XRF. However, targeted analysis with ICP-MS or similar high-precision methods of chemical analysis will be easier to perform using the P-ED-XRF results as a guide.

The present analysis has thus shown the usefulness of the P-ED-XRF-screening to localise trends worth exploring in more detail. Both analytical techniques have also shown that there is considerable variation in calcium contents. For the sake of reducing labor investment and guaranteeing consistency in firing behavior, potters usually use the same raw materials and paste recipe for most wares, changing the composition only if vessel function or meaning demanded it, or if specific raw material sources are limited or become unavailable. Differences in raw material composition noticeable for the potter - such as amount of calcium content with its significant impact on firing behavior and color - is thus usually expected to correlate with differences in other vessel properties. Surprisingly, the results presented above do not show any clear correlation between variation in calcium content and ceramic forms, periods, tempering methods, or find contexts. Higher calcium contents does, however, lead to a perceivable difference in firing color (buff/orange rather than red), and that might be a reason for a choice of clays with more or less calcium. Choosing higher-calcium material may necessitate changes in firing technology to avoid deformation, e.g., the choice for lower firing temperatures, another avenue for future research that this study has highlighted. Likewise, the great variation in ceramic pastes within a relatively small sample is puzzling. One reason might be the difference in dates and ceramic styles, suggesting differences in consumer expectations, but there are also indications that different qualities of clay may have been used for different vessel types, again a topic for future research especially on more completely preserved ceramics that allow for reliably reconstructing vessel forms.

\section{Conclusion and avenues of future research}

This pilot study has shown that the integrated use of macroscopic observations, thin-section petrography, and chemical analysis constitutes a powerful analytical strategy providing valuable insights into principles of raw material selection and production technologies of the prehistoric ceramics of northwest China. Already this small pilot study of petrographic analysis of 11 thin sections from 10 sherds and chemical analysis of 52 sherds has allowed some preliminary conclusions and pointed out avenues for future research.

For instance, it has become clear that the Majiayao fine wares from different sites in the Tao River Valley are very similar to each other in chemical composition. There is a wider spread in values only for the site of Majiayao itself, potentially due to a larger output and/or longer period of site occupation resulting in the usage of a larger number of different clay sources. It has also become clear that the criteria raw material selection and preparation as well as vessel forming, finishing, and firing for Majiayao-style fine wares are largely identical between different sites 
within the Tao River Valley, suggesting a shared craft tradition. It is unclear at present if this applies to the coarse ware, too, a question which requires further combined petrographic and chemical analyses on a wider range of archaeological and geological samples, analyses that will be conducted in collaboration between Hein and Womack.

Both petrographic and chemical analyses have furthermore already shown some continuity in the principles of raw material selection through all periods under investigation. There is significant variation only in calcium content, though not between but within the various periods and ceramic styles. The varying calcium contents of different clay sources - easily identifiable by clay color - may have been actively exploited to achieve different firing colors. It would, however, have presented a technological challenge for potters and thus merits particular attention. Our study has shown that chemical analysis alone will not be sufficient to explore this question, as secondary calcite is a rather common occurrence and can lead to sample pollution. Therefore, a combination of macroscopic, microscopic, and chemical analysis is the best approach.

Through petrographic analysis we have furthermore shown that there is continuity in tempering methods between the Majiayao and Qijia periods. This is unexpected as the change in ceramic forms and decorations as well as the advent of bronze working have previously lead scholars to assume a complete break in all aspects of life between Majiayao and Qijia. This view now has to be modified. In contrast, the Xindian material differs markedly from preceding traditions in terms of both ceramic styles and technology. While sand and crushed rock temper as well as un-tempered coarse or fine material was observed at both Majiayao and Qijiaping, Xindian is characterized by a tradition of grog temper that could have quite a long history, as the appearance of grog-in-grog indicates. When and where this history started, however, and how prevalent it is among various sites with Xindian-style material remains to be tested.

It will likewise be interesting to compare ceramics from late Qijia-period sites and sites where Xindian, Siwa, and Kayue-style ceramics have been found, as these seem to have a significant temporal overlap. It remains to be seen if Siwa and Kayue ceramics are characterized by separate technological traditions of their own, or if, in spite of their different outer appearance, they are closely related to each other and/or Xindian or Qijia, be it through a continuation or break with previous principles of raw material selection and tempering behavior.

Among the samples already analyzed here, there are furthermore two types of wares that stand out, the half-tempered/half-un-tempered Majiayao-style vessel (Ts 10-11) and the coarsetempered but intricately decorated Qijia-style handled jar (Ts 6). The former shows a conscious division between un-tempered fine ware and tempered coarse ware and also reflects a very high standard of craftsmanship and control of both forming and firing, as the risk of vessel failure with an unevenly tempered vessel would have been high. This type of two-ware vessel has gone largely unnoticed in previous research on Majiayao wares and it is thus unclear if the phenomenon is limited to this one site only, to the Tao River Valley at large, or if it was common throughout wider parts of Northwest China. This type of ceramics will thus be the subject of a separate study to be led by Stilborg in collaboration with Hein.

The remarkable Qijia vessel with its incised fine-patterned decoration on a well-smoothed but coarsely tempered ceramic body likewise merits further attention. Considering the use wear patterns, it seems to have been a cooking vessel, a function that aligns with the use of coarse temper. 
However, the intricate design and thin walls is unusual for a cooking vessel, suggesting a special function for this vessel type. The rarity of this type supports such a hypothesis. Here, residue analysis - to be conducted in the near future in collaboration with Thibaut Deviése at Oxford - will be helpful to investigate what foods or other substances were being prepared. Such analyses will provide additional insights into consumer expectations and expand the data for the contested issue of subsistence practices and eating customs in early northwest China.

\section{Acknowledgements and funding information}

We are grateful to the Museum of Far Eastern Antiquities for allowing us to work with their collections, especially Eva Myrdal who facilitated our various trips and accompanied us in our work at the MFEA, and Michael Lee who has been extremely supportive of our project at large. We could not have done our P-ED-XRF work without Sven Isaksson from the University of Stockholm who allowed us to borrow their equipment, and Markus Helfert, Goethe- Universität, Frankfurt who gave us much crucial advice on technical details and pitfalls of this form of analysis.

This research was made possible by the John Fell Fund (project ID EBD00020Ö; project title "Homogeneity in form, diversity in technique or vice versa? - Ceramic traditions in Neolithic and Bronze Age Northern China”). We are greatly indebted to the John Fell Fund and the Divisional Research Facilitators at the Social Science Division and at the School of Archaeology, University of Oxford, Armando Román Zozaya and Steve Hicks, for their support during the application process, and Julia Lee-Thorp and Chris Gosden from the School of Archaeology, University of Oxford, for their comments on our application draft. Last but by no means least, we want to thank Emily Cole for her careful editing of our paper.

\section{Appendices}

Appendix A: Petrographic data sheets

Appendix B: P-ED-XRF results

\section{References}

An, C.-B., Tang, L., Barton, L., Chen, F.-H., 2005. Climate change and cultural response around 4000 cal yr B.P. in the western part of Chinese Loess Plateau, Quaternary Research 63, 347-352.

Andersson, J.G., 1943. Researches into the prehistory of the Chinese, Museum of Far Eastern Antiquities, Stockholm.

Asplund, H., Stilborg, O., 2013. Förromersk keramikteknologi och finsk-svenska relationer Keramikteknologisk analys av Morby- och Morby-liknande keramik, Finskt Museum 2010-2011, 88-109. 
Atahan, P., Dodson, J., Li, X., Zhou, X., Hu, S., Bertuch, F., Sun, N., 2011. Subsistence and the isotopic signature of herding in the Bronze Age Hexi Corridor, NW Gansu, China, Journal of Archaeological Science 38, 1747-1753.

Bērziņš, V. 2008. Sãrnate: Living by a coastal lake during the East Baltic Neolithic. Acta Universitatis Ouluensis. B86, Oulu Oulun yliopisto, Oulu.

Bronitsky, G., Hamer, R., 1986. Experiments in ceramic technology: the effects of various tempering materials on impact and thermal shock resistence, American Antiquity 51, 89101.

Bylin-Althin, M., 1946. The Sites of Ch'i Chia P'ing and Lo Han T'ang in Kansu, Bulletin of the Museum of Far Eastern Antiquities.

Fiskesjö, M., 2014. Johan Gunnar Andersson, in: Smith, C. (Ed.), The Encyclopedia of Archaeology, Springer, New York, pp. 222-225.

Fiskesjö, M., Chen Xingcan, 2004. China before China: Johan Gunnar Andersson, Ding Wenjiang, and the discovery of China's prehistory, Museum of Far Eastern Antiquities, Stockholm.

Fitzgerald-Huber, L.G., 2003. The Qijia Culture: Paths East and West, Bulletin of the Museum of Far Eastern Antiquities.

Flad, R., Li, S., Wu, X., Zhao, Z., 2010. Early wheat in China: Results from new studies at Donghuishan in the Hexi Corridor, The Holocene 20, 955-965.

Hamer, F., Hamer, J., 2003. The potter's dictionary of materials and techniques, 5 ed., Pitman Pub.; Watson-Guptill Publications, London; New York.

Hein, A., 2016. The Problem of Typology in Chinese Archaeology, Early China, 21-52.

Helfert, M., 2013. Die portable energiedispersive Röntgenfluoreszenzanalyse (P-ED-RFA) - Studie zu methodischen und analytischen Grundlagen ihrer Anwendung in der archäologischen Keramikforschung, in: Ramminger, B., Stilborg, O., Helfert, M. (Eds.), Naturwissenschaftliche Analysen vor- und frühgeschichtlicher Keramik III: Methoden, Anwendungsbereiche, Auswertungsmöglichkeiten, Verlag Dr. Rudolf Habelt GmbH, Bonn, pp. 13-47.

Helfert, M., Böhme, D., 2010. Herkunftsbestimmung von römischer Keramik mittels portabler energiedispersiver Röntgenfluoreszenzanalyse (P-ED-RFA) : erste Ergebnisse einer anwendungsbezogenen Teststudie, Naturwissenschaftliche Analysen vor- und frühgeschichtlicher Keramik, 11-30.

Hong Lingyu 洪玲玉, Cui Jianfeng 崔劍鋒, Wang Hui 王煇, Chen Jian 陳劍, 2011. Chuanxi Majiayao leixing caitao chanyuan fenxi yu tantao 川西馬傢窯文化類型彩陶產源分析與 探討, Nanfang Minzu Kaogu 南方民族考古 Southern Ethnology and Archaeology, 1-58.

Hong Lingyu 洪玲玉, Cui Jianfeng 崔劍鋒, Chen Honghai 陳洪海, 2012. Yimin, maoyi, fangzhi yu chuangxin: Zongri yizhi xin shiqi shidai wanqi taoqi fenxi 移民、貿易、仿製創新: 
縂日遺址新時期時代晚期陶器分析, Kaoguxue yanjiu - qingzhu Yan Wenming xiansheng bashi shouchen lunwenji 考古學研究——慶祝嚴文明先生八十壽辰論文集, 242-262.

Hung Ling-yu, 2011. Pottery Production, Mortuary Practice, and Social Complexity in the Majiayao Culture, NW China (ca. 5300-4000 BP), Archaeology, Washington University in St. Louis.

Hulthén, B., 1977. On ceramic technology during the Scanian Neolithic and Bronze Age, Theses and papers in North-European Archaeology 6, Akademilitteratur, Stockholm.

Jia, X., Dong, G., Li, H., Chen, F.H., Ma, M., An, C., Brunson, K., Wang, H., Zhang, K., 2013. The development of agriculture and its impact on cultural expansion during the late Neolithic in the Western Loess Plateau, China, Holocene 23, 85-92.

La Duc, E., Chang, A., 2017. Analysis and Replication Studies of Prehistoric Chinese Ceramics from the Qijia Culture, Materials Issues in Art and Archaeology XI 2, 1849-1867.

Lin, K.-c., 2013. Pottery production and social complexity of the Bronze Age cultures and the Chengdu Plain, Sichuan, China, PhD dissertation, University of California, Los Angeles, Los Angeles.

Lindahl, A., 1990. Skärvor blir kärl - simulerad tillverkning av keramik. Levandegörande arkeologi, Rapport RA Ä 1990, 3.

Liu, F., Zhaodong, F., 2012. A dramatic climatic transition at $4000 \mathrm{cal}$. yr BP and its cultural responses in Chinese cultural domains, The Holocene 22, 1181-1197.

Smith, A.L., 2016. Pottery and Politics: Making Sense of Pottery Traditions in Central Africa, Cambridge Archaeological Journal 26, 471-491.

Mao Ruilin 毛瑞林, Xie Yan 謝炎, Qian Yaopeng 錢燿鵬, Wang Yue 王玥, 2014. Gansuo Linze Mogou mudi Siwa wenhua muzang 2009 nian fajue jianbao 甘肅臨澤磨溝寺漥文化墓葬 2009 年發掘簡報, Wenwu 文物 6, 34-38.

Mhanicka, L., 2012. Influence of Raw Materials Ratio and Sintering Temperature on the Properties of the Refractory Mullite-Corundum Ceramics, International Journal of Chemical, Molecular, Nuclear, Materials and Metallurgical Engineering 6, 194-199.

Mecking, O., Mielke, D.P., Behrendt, S., 2013. Methodenvergleich, Anwendungsbeispiele und Grundlagen der portablen Röntgenfluoreszenzanalyse (P-RFA) in der Keramikforschung, in: Ramminger, B., Stilborg, O., Helfert, M. (Eds.), Naturwissenschaftliche Analysen vorund frühgeschichtlicher Keramik III: Methoden, Anwendungsbereiche, Auswertungsmöglichkeiten, Verlag Dr. Rudolf Habelt GmbH, Bonn, pp. 49-67.

Nössler, D., Stilborg, O., 2010. Shape und Ware: Note on a progressing study of Iron Age and Early Medieval pottery from Flögeln-Eekhöltjen and Loxstedt-Littstücke in the ElbeWeser-Triangle, in: Ramminger, B., Stilborg, O. (Eds.), Naturwissenschaftliche Analysen vor- und frühgeschichtlicher Keramik I: Methoden, Anwendungsbereiche, 
Auswertungsmöglichkeiten, Universitätsforschungen zur Prähistorischen Archäologie Band 176, Verlag Dr. Rudolf Habelt GmbH, Bonn, pp. 101-115.

Pak, Y., 1995. A study of the Bronze Age culture in the northern zone of China, PhD dissertation, Department of Anthropology, Harvard University, Harvard.

Papmehl-Dufay, L., Stilborg, O, Lindahl, A., Isaksson, S., 2013. For everyday use and special occasions: A multi-analytical study of pottery from two Early Neolithic Funnel Beaker (TRB) sites on the island of Öland, SE Sweden. In Ramminger et. al. (Eds). Naturwissenschaftliche Analysen vor- und frühgeschichtlicher Keramik III. Methoden, Anwendungsbereiche, Auswertungsmöglichkeiten, Universitätsforschungen zur Prähistorischen Archäologie Band 238, Verlag Dr. Rudolf Habelt GmbH, Bonn, pp. 123152.

Peacock, D.P.S. 1982. Pottery in the Roman World: An Ethnoarchaeological Approach, Longman, London

Quinn, P.S., 2013. Ceramic petrography: the interpretation of archaeological pottery \& related artefacts in thin section, Archaeopress, Oxford.

Quinn, P.S., Zhang, S., Xia, Y., Li, X., 2017. Building the Terracotta Army: ceramic craft technology and organisation of production at Qin Shihuang's mausoleum complex, Antiquity 91, 966-979.

Ren Ruibo 任瑞波, Chen Wei 陳葦, Ren Yunjian 任斑娟, 2013. Chuanxi caitao chandi laiyuan xinshuo jiantan 川西彩陶产地来源新说检讨, Sichuan wenwu 四川文物 2, 40-45.

Salminen, R., 2006. Geochemical atlas of Europe. Part 1, Background information, methodology and maps, Geological Survey of Finland, Espo.

Shepard, A.O., 1968. Ceramics for the archaeologist, Carnegie Institution of Washington, Washington, D.C.

Shui Tao 水濤, 2001. Zhongguo xibei diqu qingtong shidai kaogu lunji 中國西北地區青銅時代 考古論集. Papers on the Bronze Age Archaeology of Northwest China, Kexue Chubanshe 科學出版社, Beijing.

Stilborg, O., 2012. On the other side. A case of cultural encounter between the Pitted Ware Culture and the Battle Axe Culture in Eastern Sweden, in: Ramminger, B., Stilborg, O. (Eds.), Naturwissenschaftliche Analysen vor- und frühgeschichtlicher Keramik II: Methoden, Anwendungsbereiche, Auswertungsmöglichkeiten. Dritter und vierter internationaler Workshop für junge Wissenchaftlerinnen und Wissenschaftler in Hamburg am 13. Februar 2010 und 5. Februar 2011, Verlag Dr. Rudolf Habelt GmbH, Bonn, pp. 141-158.

Stilborg, O., 2017. Pottery craft tradition in transition: From Neolithic China to Bronze Age northern Sweden. Journal of Archaeological Science: Reports 16, 658-664

Stoltman, J.B., Jing, Z., Tang, J., Rapp, G., 2009. Ceramic Production in Shang Societies of Anyang, Asian Perspectives 48, 182-203. 
Stoltman, J.B., Yue, Z., Jing, Z., Tang, J., Burton, J.H., Raudsepp, M., 2018. New insights into the composition and microstructure of ceramic artifacts associated with the production of Chinese bronzes at Yinxu, the last capital of the Shang dynasty, Archaeological Research in Asia.

Thér, R., 2016. Identification of Pottery-Forming Techniques using Quantitative Analysis of the Orientation of Inclusions and Voids in Thin Sections, Archaeometry 58, 222-238.

Van Thienen, V., Stilborg, O., Agricola, C., Heeren, S., 2017. Characterising terra nigra footvessels of the late roman period (4th-5th century) from Germany, the Netherlands and Belgium, Archaologisches Korrespondenzblatt 47, 87-106.

Wenger, E., 1998. Communities of practice: learning, meaning, and identity, Cambridge University Press, Cambridge, U.K.; New York, N.Y.

Womack, A., 2017. Crafting community, exploring identity and interaction through ceramics in late Neolithic and early Bronze Age northwest China, Department of Anthroplogy, Yale University.

Womack, A., Jaffe, Y., Zhou, J., Hung, L.-y., Wang, H., Li, S., Chen, P., Flad, R., 2017. Mapping Qijiaping: New Work on the Type-Site of the Qijia Culture (2300-1500 B.C.) in Gansu Province, China, Journal of Field Archaeology 42, 488-502.

Woods, A., 1984. Use of tangential thin sections on experimental and archaeological material, Bulletin of the Experimental Firing Group 3, 108-114.

Worrall, W.E., 1986. Clays and ceramic raw materials, Elsevier Applied Science Publishers: London.

Wu, W., Liu, T., 2004. Possible role of the Holocene Event 3 on the collapse of Neolithic Cultures around the Central Plain of China, Quaternary International 117, 153-166. 